\title{
The enthalpies of mixing of ternary liquid Ag-Ca-Ge alloys
}

\author{
Michael Ivanov ${ }^{\mathrm{a}}$, Natalia Kotova ${ }^{\mathrm{b}^{*}}$, Natalia Usenko ${ }^{\mathrm{b}}$ \\ ${ }^{a}$ Frantsevich Institute for Problems of Materials Science, Kyiv, Krzhizhanovsky Street, 3, 03680, \\ Kyiv-142, Ukraine \\ ${ }^{b}$ Department of Chemistry, Taras Shevchenko National University of Kyiv, Volodymyrska Street, \\ 64/13, Kyiv 01601, Ukraine \\ nkotova61@gmail.com
}

Keywords: calcium, germanium, silver, high temperature calorimetry, enthalpy of mixing Partial and integral enthalpies of mixing of the ternary $\mathrm{Ag}-\mathrm{Ca}-\mathrm{Ge}$ melts were determined for the first time by the high-temperature isoperibolic calorimetry at 1300-1550 K. The experiments were performed for six sections with a constant ratio of two components up to the molar fraction of the third component equal to 0.3 . The enthalpies of mixing in this ternary system are exothermic values which increase in absolute value from the Ag corner of the concentration triangle towards the constituent binary $\mathrm{Ca}-\mathrm{Ge}$ system. The minimum value of the integral enthalpy of mixing was obtained for $\mathrm{Ca}_{0.6} \mathrm{Ge}_{0.4}$ composition of the $\mathrm{Ca}-\mathrm{Ge}$ binary system (about $-58.00 \mathrm{~kJ} \mathrm{~mol}^{-1}$ ). The enthalpies of mixing of the ternary $\mathrm{Ag}-\mathrm{Ca}-\mathrm{Ge}$ melts are calculated for the whole concentration triangle by the Redlich-Kister-Muggianu method, taking into account the term of specific ternary interaction defined from our experimental data. The topology of the isoenthalpies of mixing is determined.

\section{Introduction}

The high-temperature synthesis from the liquid state is among the most common ways to obtain modern materials. Naturally, the properties of such materials strongly depend on the structure, thermodynamic and other physicochemical parameters of the melt, as well as on the processes occurring when the composition and temperature change. For example, the set of characteristics of most traditional metal alloys is determined by nature, number, and sequence of crystalline phases formation during solidification of the liquid, in other words by the regularities of its thermodynamic functions. The study of $\mathrm{Ag}-\mathrm{Ca}$ alloys is a part of a global trend in the development of science aimed at "green" technologies, such as hydrogen energy in the context of its application in the automotive industry and in the creation of environmental energy sources. Alloys containing germanium are well known as semi- and superconductors. The use of these materials requires knowledge of phase equilibria and thermodynamic properties 
of alloys in germanium-containing systems, in particular, the $\mathrm{Ca}-\mathrm{Ge}$ one. A number of stable refractory compounds are formed in the $\mathrm{Ca}-\mathrm{Ge}$ system. However, their increased tendency to hydrolysis and oxidation in humid air and, in addition, the significant volatility of calcium at temperatures at which the alloys are liquid, impedes their effective use. The open air instability of $\mathrm{Ca}-\mathrm{Ge}$ alloy samples motivates a search for some alloying components that can make them more resistant. The Ag-Ge system has been widely studied as basic system or as a constituent of various multicomponent systems. The Ag-based alloys are of industrial importance due to their use as high-temperature solders in jewellery or soldering alloys for thermoelectric modules.

The Ag-Ca system. The most recent and complete critical analysis and modelling of the thermodynamic properties of liquid and solid Ag-Ca alloys were carried out in [1]. In [2] the standard enthalpies of formation of the solid $\mathrm{Ag}$ Ca alloys $\left(\Delta H_{f}\right)$ were determined. The calculated phase diagram of this system is presented in [3]. Six stoichiometric intermetallic phases are formed in the system, two of them, namely $\mathrm{Ca}_{2} \mathrm{Ag}_{7}\left(\mathrm{~T}_{\mathrm{m}}=1004 \mathrm{~K}\right)$ and $\mathrm{CaAg}\left(\mathrm{T}_{\mathrm{m}}=938 \mathrm{~K}\right)$ being congruently melting ones. The values of the standard enthalpies of formation of these intermetallic compounds are -18.8 and $-28 \mathrm{~kJ}$ $\mathrm{mol}^{-1}$, respectively according to [2]. The enthalpies of mixing of liquid alloys of this system were determined in [4] at $1300 \mathrm{~K}$ for the entire composition range by high-temperature isoperibol calorimetry, which usually provides the most reliable value. The concentration dependence of the enthalpy of mixing of the $\mathrm{Ag}-$ Ca melts, according to [4], is given as follows, $\left(\mathrm{kJ} \mathrm{mol}{ }^{-1}\right)$ :

$$
\begin{gathered}
\Delta H_{\mathrm{Ag}-\mathrm{C}}=x_{\mathrm{Ag}}\left(1-x_{\mathrm{Ag}}\right)(-63.1- \\
74.1 x_{\mathrm{Ag}}+270.3 x_{\mathrm{Ag}}^{2}-954.4 x_{\mathrm{Ag}}^{3}+ \\
\left.1183.3 x_{\mathrm{Ag}}^{4}-450.6 x_{\mathrm{Ag}}^{5}\right)
\end{gathered}
$$

The Ca-Ge system. The phase diagram of the $\mathrm{Ca}-\mathrm{Ge}$ system was studied in [5]. There are 5 intermetallic phases in the system, two of them, namely $\mathrm{Ca}_{2} \mathrm{Ge}\left(\mathrm{T}_{\mathrm{m}}=1583 \mathrm{~K}\right)$ and $\mathrm{CaGe}\left(\mathrm{T}_{\mathrm{m}}=\right.$ $1483 \mathrm{~K})$, melting congruently. The thermodynamic properties of liquid and solid alloys of this system have been studied in a number of works by various experimental methods. It should be noted that information from different sources may differ significantly. Therefore, in [6], a recent detailed critical analysis of the available literature information on thermodynamic properties of this system was carried out. In this paper the enthalpies of mixing of liquid alloys in the concentration range $0<x_{\mathrm{Ge}}$ $<0.08$ at $1270-1300 \mathrm{~K}$ and $0.54<x_{\mathrm{Ge}} \cdot<1$ at 1370-1520 K were also experimentally determined via high-temperature calorimetry [6]. Alloy formation was shown to be accompanied by significant exothermic effects: $\Delta H_{\min }=-58.2$ $\mathrm{kJ} \mathrm{mol}^{-1}$ at $x_{\mathrm{Ge}}=0.4$, the partial enthalpies of mixing of the components at infinite dilution being equal to $\Delta \bar{H}_{\mathrm{Ca}}^{\infty}=-138, \Delta \bar{H}_{\mathrm{Ge}}^{\infty}=-200 \mathrm{~kJ}$ $\mathrm{mol}^{-1}$ (at $1300 \mathrm{~K}$ ). The other thermodynamic 
functions of liquid phase, such as Gibbs energy, entropy of mixing, activity of components were calculated for a wide temperature range using ideal and regular associated solution models. The interpolation equation for the concentration dependence of the enthalpy of mixing of the $\mathrm{Ca}-$ Ge melts at $1300 \mathrm{~K}$ is presented in [6] as follows, $\left(\mathrm{kJ} \mathrm{mol}^{-1}\right)$ :

$$
\Delta H_{\mathrm{Ca}-\mathrm{Ge}}=x_{\mathrm{Ge}}\left(1-x_{\mathrm{Ge}}\right)\left(-199.8-351.7 x_{\mathrm{Ge}}+\right.
$$
$\left.228.6 x_{\mathrm{Ge}}^{2}+2023.7 x_{\mathrm{Ge}}^{3}-3202 x_{\mathrm{Ge}}^{4}++1363.6 x_{\mathrm{Ge}}^{5}\right)$.

The Ag-Ge system. The thermodynamic properties of this system have been largely studied. The most recent and detailed thermodynamic assessment of the binary $\mathrm{Ag}-\mathrm{Ge}$ system is performed in $[8,9]$. The phase diagram of this system is of a simple eutectic type [10]. However, a mixing effect in this system is accompanied by both exothermic and endothermic enthalpies, depending on the composition. The formation of Ag-rich alloys is accompanied by exothermic effects and heterocoordinated associates can form in the liquid phase $[11,12]$. At the same time, the Gerich alloys and those of intermediate composition demonstrate positive values of enthalpies of mixing [13-15]. For the thermodynamic modelling of this system by the CALPHAD method performed in $[8,9]$, the authors used the data from the reference book [15] and the results on the enthalpies of mixing from [14], where $\Delta H$ were calculated from the activities of components measured by the electromotive force method. We have performed the joint mathematical processing of the data [14] and [15] using the least-squares method and obtained a power polynomial for calculating the enthalpy of mixing of liquid $\mathrm{Ag}-\mathrm{Ge}$ alloys in the entire concentration region at $1430 \mathrm{~K},\left(\mathrm{~kJ} \mathrm{~mol}^{-1}\right)$ :

$$
\begin{gathered}
\Delta H_{\mathrm{Ag}-\mathrm{Ge}}=x_{\mathrm{Ag}}\left(1-x_{\mathrm{Ag}}\right)\left(16.3-2.4 x_{\mathrm{Ag}}-539.5 x_{\mathrm{Ag}}^{2}+\right. \\
4238.9 x_{\mathrm{Ag}}^{3}--14166.3 x_{\mathrm{Ag}}^{4}+23361.8 x_{\mathrm{Ag}}^{5}- \\
\left.18804.2 x_{\mathrm{Ag}}^{6}+5882.8 x_{\mathrm{Ag}}^{7}\right)
\end{gathered}
$$

The extreme values of the integral enthalpy of mixing for the $\mathrm{Ag}-\mathrm{Ge}$ melts are: $\Delta H_{\min }=-1.1 \mathrm{~kJ} \mathrm{~mol}^{-1}$ at $x_{\mathrm{Ge}}=0.1, \Delta H_{\max }=2.3$ $\mathrm{kJ} \mathrm{mol}^{-1}$ at $x_{\mathrm{Ge}}=0.7$.

Figure 1 demonstrates the concentration dependences of the integral enthalpies of mixing for liquid alloys of the constituent binary systems $\mathrm{Ag}-\mathrm{Ge}, \mathrm{Ag}-\mathrm{Ca}$, and $\mathrm{Ca}-\mathrm{Ge}$.

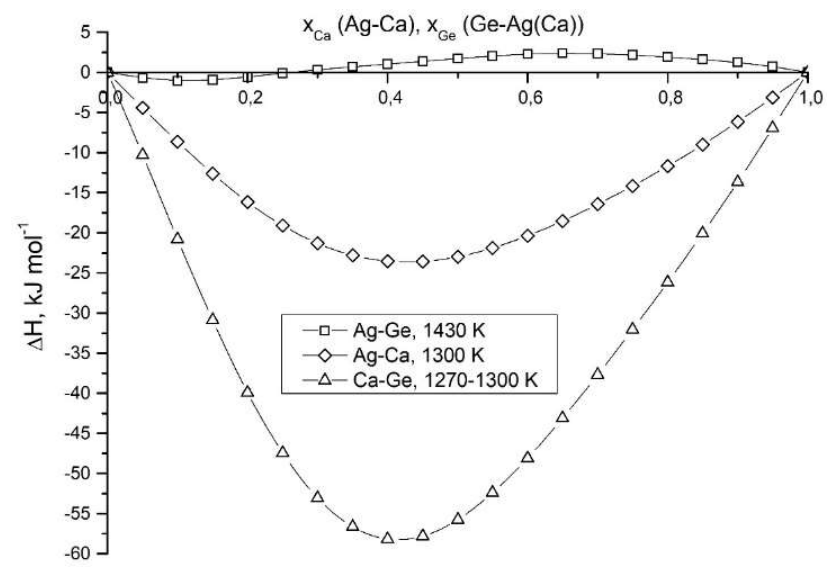

Figure 1. Concentration dependences of the integral enthalpies of mixing for liquid alloys of the boundary binary systems.

The phase diagram and the thermodynamic properties of the ternary $\mathrm{Ag}-\mathrm{Ca}-$ Ge system have not been studied previously.

The purpose of this study is the calorimetric determination of the enthalpies of 
mixing of liquid alloys of the ternary $\mathrm{Ag}-\mathrm{Ca}-\mathrm{Ge}$ system.

\section{Experimental part}

The experiments were carried out in a high temperature solution calorimeter in purified helium medium under a pressure of $2 \cdot 10^{5} \mathrm{~Pa}$ at 1300-1550 K. The apparatus and experimental technique were similar to those employed in previous investigations $[16,17]$. The purity of elements used in the experiments was $99.99 \%$ for $\mathrm{Ge}$ and $\mathrm{Ag}$, 99.9\% for $\mathrm{Ca}$ and $\mathrm{W}$ (material for calibration).

Alumina crucibles lined with yttrium oxide and heat-treated at $1500 \mathrm{~K}$ were used as containers for the melt in the experiments with the initial binary $\mathrm{Ag}-\mathrm{Ge}(\mathrm{Ca})$ melts. In the case of the initial Ge-Ca alloys, molybdenum crucibles were used. The calcium samples were mechanically processed just before the experiments and were stored in petroleum ether to prevent oxidation; samples were prepared in a box filled with purified helium.

The partial heats of mixing of the components were measured during successive introduction of metal samples $(\mathrm{Ca}, \mathrm{Ge}$, and $\mathrm{Ag}$ ) taken at $298 \mathrm{~K}$ into a calorimetric bath (pure liquid metal or an alloy placed in a crucible). The initial mass of metal in the bath ranged from 1.5 to $3 \mathrm{~g}$. The masses of the samples were within $0.01-0.03 \mathrm{~g}$. The change in alloy concentration after each addition was less than 1.5 at. \%. Thus, we determined the partial molar enthalpies of the components with sufficient accuracy.
The experimental method is based on measuring the temperature difference $\Delta T$ between the test and the reference samples (the reference is a crucible containing $\mathrm{W}$ ), plotted as a function of the temperature relaxation time $(t)$. The temperature measurements were carried out using WRe5/WRe20 thermocouples.

The resulting heat balance for the endothermic effect is:

$$
k \int \Delta T(t) d T=\Delta H_{i, 298}^{T}+\Delta \bar{H}_{i}
$$

where $k$ is the molar thermal equivalent of the calorimeter; $\Delta H_{i, 298}^{T}$ is the enthalpy change for heating of 1 mole of metal dropped into the bath from $298 \mathrm{~K}$ to the temperature of liquid bath, computed from the Ref. [18]; $\Delta \bar{H}_{i}$ is the unknown partial molar enthalpy of mixing of component. The values of the high-temperature standard enthalpy $\Delta H_{i, 298}^{T}$ of metals used in the experiments contained a contribution from the enthalpy of melting of the component. Thus, the liquid components were taken as the standard state. Molar thermal equivalent of the calorimeter was determined in calibrating droppings at the beginning (using the same component as that in the bath) and at the end (using specimens of W) of each experimental series. We assumed that there is a linear concentration dependence for $k$ in all experimental series.

The set of the experimental data points computed from Eq. (4) was treated statistically (in the form of a partial $\alpha_{i}$-function defined as $\left.\alpha_{i}=\Delta \bar{H}_{i}\left(1-x_{i}\right)^{-2}\right)$ by a least-squares analysis using Forsythe orthogonal polynomials and 
applying the $F$-test for a correct choice of polynomial degree [19]. Finally, the $\alpha_{i}$-function was represented as a polynomial series as follows:

$$
\alpha_{i}=q_{0}+q_{1} x_{i}+q_{2} x_{i}^{2}+\cdots+q_{j} x_{i}^{j} .
$$

where $q_{j}$ are the polynomial coefficients, $j$ is the polynomial degree.

For the ternary system $\mathrm{Ag}-\mathrm{Ca}-\mathrm{Ge}$, the partial molar enthalpies of calcium $\left(\Delta \bar{H}_{\text {Ca }}\right)$ were measured along the section with a constant ratio of the molar fractions of silver and germanium $x_{\mathrm{Ag}} / x_{\mathrm{Ge}}$; the partial molar enthalpies of germanium $\left(\Delta \bar{H}_{\mathrm{Ge}}\right)$ were determined along three sections with a constant ratio of the molar fractions of silver and calcium $x_{\mathrm{Ag}} / x_{\mathrm{Ca}}$; the partial molar enthalpies of mixing of silver $\left(\Delta \bar{H}_{\mathrm{Ag}}\right)$ were measured along two sections with a constant ratio of the molar fractions of calcium and germanium $x_{\mathrm{Ca}} / x_{\mathrm{Ge}}$. To obtain the partial molar enthalpies of the components in the ternary system, small samples of a metal were introduced into calorimetric bath containing binary melt with selected ratios of the other two components.

For the ternary system the Darken method [19] gives the following expression for the integral enthalpy of mixing:

$$
\Delta H=\left(1-x_{3}\right)\left(\int_{x_{3}=0}^{x_{3}} \alpha_{3} d x_{3}+\Delta H_{x_{3}=0}\right)_{x_{1} / x_{2}},
$$

where $\Delta H_{x_{3}=0}$ is the integral molar enthalpy of mixing of corresponding binary $\mathrm{Me}_{1}-\mathrm{Me}_{2}$ liquid alloy (with the above indicated molar fractions ratio $\left.x_{1} / x_{2}\right)$.
To determine the course of the enthalpies of mixing in the entire concentration range, we also described our experimental data on the integral enthalpies of mixing of the ternary Ag$\mathrm{Ca}-\mathrm{Ge}$ alloys by the least-squares method according to the regular solution model using the Redlich-Kister-Muggianu polynomials [20] as follows:

$$
\begin{aligned}
& \Delta H\left(x_{\mathrm{Ag}}, x_{\mathrm{Ca}}, x_{\mathrm{Ge}}\right)= \\
& =x_{\mathrm{Ca}} x_{\mathrm{Ag}} \sum_{i=0}^{n} L_{\mathrm{Ca}-\mathrm{Ag}}\left(x_{\mathrm{Ca}}-x_{\mathrm{Ag}}\right)^{i}+ \\
& +x_{\mathrm{Ge}} x_{\mathrm{Ag}} \sum_{i=0}^{n} L_{\mathrm{Ge}-\mathrm{Ag}}\left(x_{\mathrm{Ge}}-x_{\mathrm{Ag}}\right)^{i}+ \\
& \quad+x_{\mathrm{Ge}} x_{\mathrm{Ca}} \sum_{i=0}^{n} L_{\mathrm{Ge}-\mathrm{Ca}}\left(x_{\mathrm{Ge}}-x_{\mathrm{Ca}}\right)^{i}+ \\
& +x_{\mathrm{Ca}} x_{\mathrm{Ag}} x_{\mathrm{Ge}}\left(x_{\mathrm{Ca}}{ }^{0} L_{\mathrm{Ag}-\mathrm{Ca}-\mathrm{Ge}}+x_{\mathrm{Ag}}{ }^{1} L_{\mathrm{Ag}-\mathrm{Ca}-\mathrm{Ge}}+x_{\mathrm{Ge}}{ }^{2} L_{\mathrm{Ag}-\mathrm{Ca}-\mathrm{Ge}}\right)
\end{aligned}
$$

where ${ }^{i} L_{\mathrm{Ca}-\mathrm{Ag}},{ }^{i} L_{\mathrm{Ge}-\mathrm{Ag}}$, and ${ }^{i} L_{\mathrm{Ge}-\mathrm{Ca}}$ are the coefficients of the Redlich-Kister polynomials for the corresponding boundary binary systems; $n$ are the degrees of polynomials, ${ }^{0} L_{\mathrm{Ag}-\mathrm{Ca}-\mathrm{Ge}}$, ${ }^{1} L_{\mathrm{Ag}-\mathrm{Ca}-\mathrm{Ge}}$ and ${ }^{2} L_{\mathrm{Ag}-\mathrm{Ca}-\mathrm{Ge}}$ are parameters of specific ternary interaction for describing the properties of a ternary system according to the RedlichKister-Muggianu method. Redlich-Kister parameters for binary systems are obtained by converting the corresponding power polynomials into Redlich-Kister polynomials.

\section{Results and discussion}

The partial enthalpies of mixing of the components were measured for:

- calcium $\left(\Delta \bar{H}_{\mathrm{Ca}}\right)$ along the section of the concentration triangle with a constant ratio of the molar fractions of silver and germanium 
$x_{\mathrm{Ag}} / x_{\mathrm{Ge}}=0.30 / 0.70$ at $1300 \mathrm{~K}$ to the mole fraction of calcium in the ternary alloy 0.2 ;

- germanium $\left(\Delta \bar{H}_{\mathrm{Ge}}\right)$ along the sections of the concentration triangle with a constant ratio of the molar fractions of silver and germanium $x_{\mathrm{Ag}} / x_{\mathrm{Ca}}=0.25 / 0.75,0.50 / 0.50$ and $0.80 / 0.20$ at $1300 \mathrm{~K}$ to the mole fraction of germanium in the ternary alloy 0.3 ;

- silver $\left(\Delta \bar{H}_{\mathrm{Ag}}\right)$ along the sections of the concentration triangle with a constant ratio of the molar fractions of calcium and germanium $x_{\mathrm{Ca}} / x_{\mathrm{Ge}}=0.80 / 0.20$ at $1550 \mathrm{~K}$ and $0.30 / 0.70$ at $1500 \mathrm{~K}$ to the mole fraction of silver in the ternary alloy 0.3 .

The experimental points of $\Delta \bar{H}_{\mathrm{Ca}}, \Delta \bar{H}_{\mathrm{Ge}}$ and $\Delta \bar{H}_{\mathrm{Ag}}$ with smoothing curves for all investigated cross sections are shown in Figure 2 (a, b, c). Figure 2 demonstrates that for the section $x_{\mathrm{Ag}} / x_{\mathrm{Ca}}=0.25 / 0.75$ the partial enthalpy of mixing of germanium at infinite dilution $\Delta \bar{H}_{\mathrm{Ge}}^{\infty}$ is the largest in absolute value $\left(-166 \mathrm{~kJ} \mathrm{~mol}^{-1}\right)$, then there is $\Delta \bar{H}_{\mathrm{Ca}}^{\infty}$ for the section $x_{\mathrm{Ag}} / x_{\mathrm{Ge}}=$ $0.3 / 0.7$, equal to $-117 \mathrm{~kJ} \mathrm{~mol}^{-1}$; the smallest values are $\Delta \bar{H}_{\mathrm{Ge}}$ for the section $x_{\mathrm{Ag}} / x_{\mathrm{Ca}}=0.8 / 0.2$ $\left(-17 \mathrm{~kJ} \mathrm{~mol}^{-1}\right)$ and $\Delta \bar{H}_{\mathrm{Ag}}$ for the section $x_{\mathrm{Ca}} / x_{\mathrm{Ge}}$ $=0.3 / 0.7\left(-8 \mathrm{~kJ} \mathrm{~mol}^{-1}\right)$.

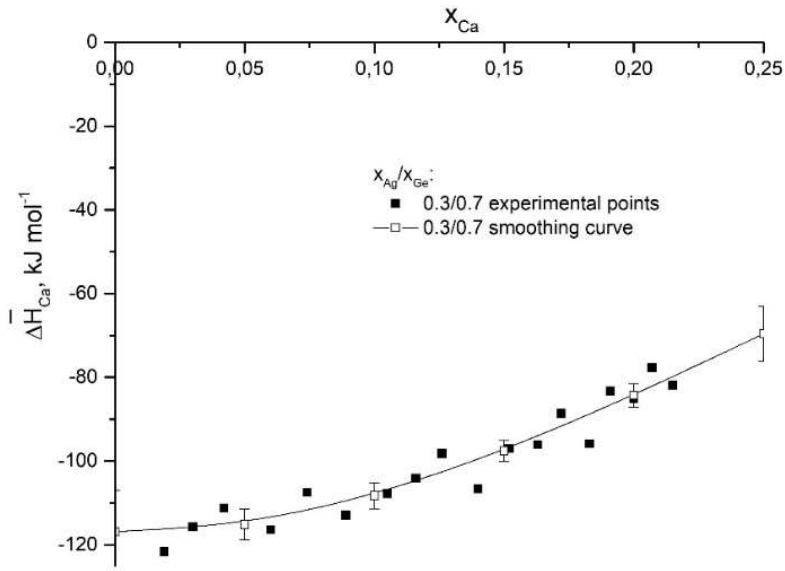

a)

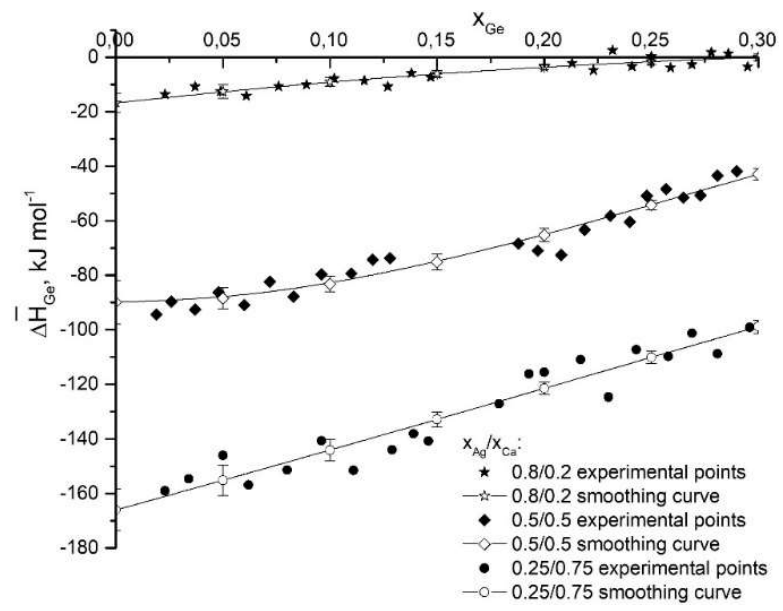

b)

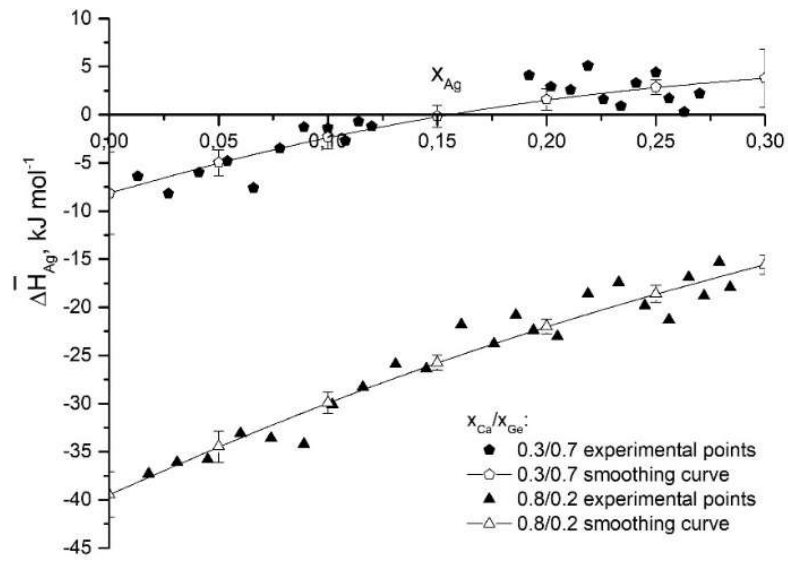

c)

Figure 2. Experimental data and approximating functions for the partial enthalpies of mixing of components in ternary Ag-Ca-Ge melts: a) $\Delta \bar{H}_{\mathrm{Ca}}$ at $1300 \mathrm{~K}$; b) $\Delta \bar{H}_{\mathrm{Ge}}$ at $1300 \mathrm{~K}$ and c) $\Delta \bar{H}_{\text {Ag }}$ at $1500-1550 \mathrm{~K}$.

The smoothed values of the partial enthalpies for calcium, germanium, and silver, as 
well as the integral enthalpy of mixing for liquid

$\mathrm{Ag}-\mathrm{Ca}-\mathrm{Ge}$ alloys with the corresponding confidence intervals are given in Table 1.
The integral enthalpies of mixing calculated along the investigated cross sections are shown in Figure 3.

Table 1. The partial enthalpies of mixing of calcium, germanium and silver and the integral enthalpies for liquid Ag-Ca-Ge alloys at $1300-1550 \mathrm{~K}, \mathrm{~kJ} \mathrm{~mol}^{-1}$

\begin{tabular}{|c|c|c|c|c|c|c|}
\hline \multirow[t]{3}{*}{$x_{G e}$} & \multicolumn{3}{|c|}{$\begin{array}{l}\qquad \Delta \bar{H}_{G e} \\
\text { for sections } x_{A g} / x_{C a}=\mathrm{const}\end{array}$} & \multirow[t]{3}{*}{$x_{A g}$} & \multicolumn{2}{|c|}{$\begin{array}{l}\qquad \Delta \bar{H}_{A g} \\
\text { for sections } x_{C a} / x_{G e}=\mathrm{const}\end{array}$} \\
\hline & $0.25 / 0.75$ & $0.50 / 0.50$ & $0.80 / 0.20$ & & $0.30 / 0.80$ & $0.80 / 0.20$ \\
\hline & \multicolumn{3}{|c|}{$1300 \mathrm{~K}$} & & $1500 \mathrm{~K}$ & $1550 \mathrm{~K}$ \\
\hline 0 & $-166.1 \pm 7.6$ & $-89.9 \pm 8.1$ & $-16.8 \pm 3.4$ & 0 & $-8.2 \pm 4.3$ & $-39.5 \pm 2.4$ \\
\hline 0.05 & $-155.2 \pm 5.6$ & $-88.4 \pm 3.8$ & $-12.6 \pm 2.5$ & 0.05 & $-5.0 \pm 1.3$ & $-34.5 \pm 1.6$ \\
\hline 0.10 & $-144.1 \pm 3.9$ & $-83.1 \pm 2.9$ & $-9.1 \pm 1.7$ & 0.10 & $-2.3 \pm 1.2$ & $-29.9 \pm 1.1$ \\
\hline 0.15 & $-132.9 \pm 2.8$ & $-75.1 \pm 2.9$ & $-6.1 \pm 1.2$ & 0.15 & $-0.1 \pm 1.2$ & $-25.7 \pm 0.8$ \\
\hline 0.20 & $-121.5 \pm 2.3$ & $-65.2 \pm 2.5$ & $-3.6 \pm 1.0$ & 0.20 & $1.6 \pm 1.1$ & $-22.0 \pm 0.7$ \\
\hline 0.25 & $--110.1 \pm 2.2$ & $-54.2 \pm 1.8$ & $-1.6 \pm 1.1$ & 0.25 & $2.9 \pm 0.8$ & $-18.6 \pm 0.9$ \\
\hline 0.30 & $-98.8 \pm 2.5$ & $-42.9 \pm 2.1$ & $-0.01 \pm 1.2$ & 0.30 & $3.8 \pm 3.0$ & $-15.6 \pm 1.0$ \\
\hline \multirow[t]{2}{*}{$x_{G e}$} & \multicolumn{3}{|c|}{$\begin{array}{c}\Delta H \\
\text { for sections } x_{A g} / x_{C a}=\text { const }\end{array}$} & \multirow[t]{2}{*}{$x_{A g}$} & \multicolumn{2}{|c|}{$\begin{array}{c}\Delta H \\
\text { for sections } x_{C a} / x_{G e}=\text { const }\end{array}$} \\
\hline & $0.25 / 0.75$ & $0.50 / 0.50$ & $0.80 / 0.20$ & & $0.30 / 0.70$ & $0.80 / 0.20$ \\
\hline 0 & $-14.2 \pm 0.5$ & $-22.9 \pm 0.8$ & $-16.2 \pm 0.7$ & 0 & $-37.7 \pm 3.8$ & $-39.9 \pm 4.0$ \\
\hline 0.05 & $-21.5 \pm 0.7$ & $-26.2 \pm 0.9$ & $-16.1 \pm 0.8$ & 0.05 & $-36.1 \pm 3.7$ & $-39.8 \pm 3.9$ \\
\hline 0.10 & $-28.2 \pm 0.8$ & $-29.4 \pm 1.0$ & $-15.8 \pm 0.9$ & 0.10 & $-34.4 \pm 3.6$ & $-39.4 \pm 3.8$ \\
\hline 0.15 & $-34.3 \pm 0.9$ & $-32.2 \pm 1.2$ & $-15.4 \pm 0.9$ & 0.15 & $-32.6 \pm 3.5$ & $-38.7 \pm 3.6$ \\
\hline 0.20 & $-39.8 \pm 0.9$ & $-34.4 \pm 1.3$ & $-14.8 \pm 0.9$ & 0.20 & $-30.6 \pm 3.4$ & $-37.8 \pm 3.5$ \\
\hline 0.25 & $-44.5 \pm 1.1$ & $-36.0 \pm 1.2$ & $-14.0 \pm 1.0$ & 0.25 & $-28.6 \pm 3.3$ & $-36.7 \pm 3.5$ \\
\hline 0.30 & $-48.5 \pm 1.4$ & $-36.8 \pm 1.5$ & $-13.1 \pm 1.1$ & 0.30 & $-26.4 \pm 4.3$ & $-35.4 \pm 3.6$ \\
\hline
\end{tabular}

\begin{tabular}{|c|c|c|}
\hline \multirow{2}{*}{$x_{C a}$} & $\Delta \bar{H}_{C a}$ & $\Delta H$ \\
\cline { 2 - 3 } & for section $x_{A g} / x_{G e}=0.30 / 0.70,1300 \mathrm{~K}$ \\
\hline 0 & $-116.9 \pm 9.8$ & $2.3 \pm 0.2$ \\
\hline 0.05 & $-115.2 \pm 3.7$ & $-3.6 \pm 0.4$ \\
\hline 0.10 & $-108.3 \pm 3.1$ & $-9.3 \pm 0.6$ \\
\hline 0.15 & $-97.6 \pm 2.5$ & $-14.5 \pm 0.6$ \\
\hline 0.20 & $-84.3 \pm 2.8$ & $-19.0 \pm 0.9$ \\
\hline 0.25 & $-69.6 \pm 6.6$ & $-22.6 \pm 2.4$ \\
\hline
\end{tabular}




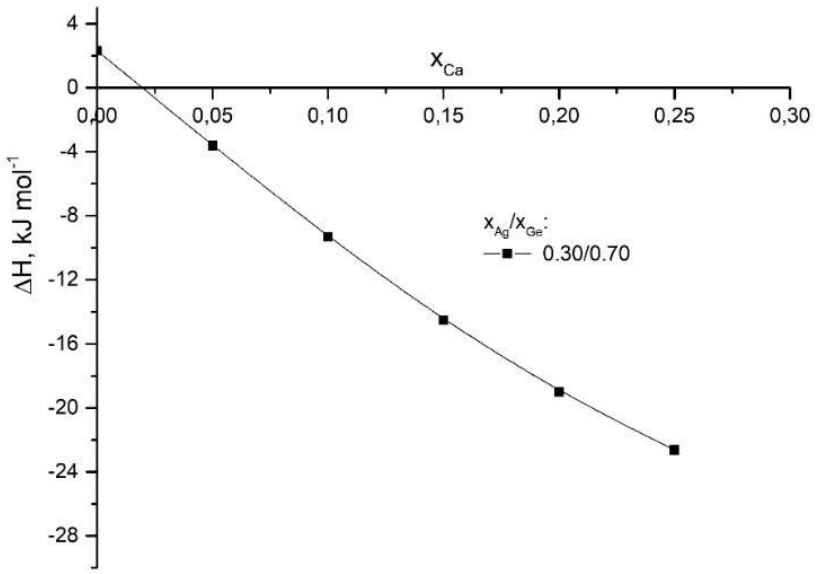

a)

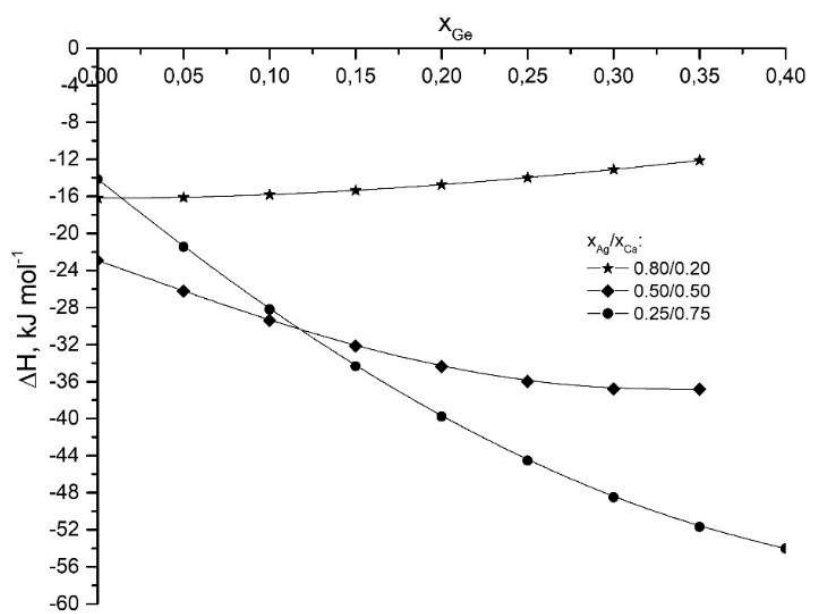

b)

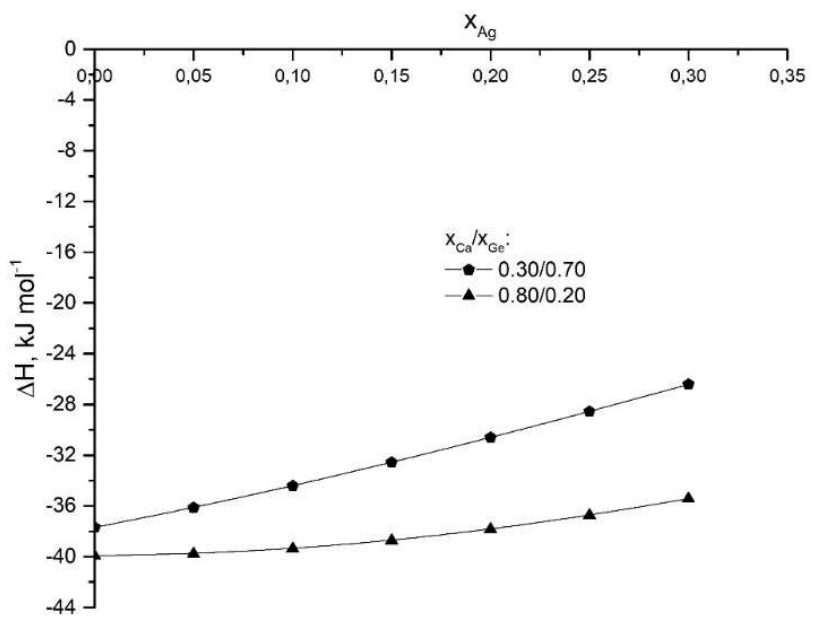

c)

Figure 3. The integral enthalpies of mixing of liquid $\mathrm{Ag}-$ $\mathrm{Ca}-\mathrm{Ge}$ ternary alloys at $1300-1550 \mathrm{~K}$ plotted along the investigated cross sections with constant ratio $x_{\mathrm{Ag}} / x_{\mathrm{Ge}}(\mathrm{a})$, $x_{\mathrm{Ag}} / x_{\mathrm{Ca}}(\mathrm{b})$ and $x_{\mathrm{Ca}} / x_{\mathrm{Ge}}(\mathrm{c})$
Approximating polynomials for the integral enthalpies of mixing along these sections are given in Table 2.

Table 2. Approximating polynomials for the integral enthalpies of mixing $\Delta H$ along corresponding sections of the ternary $\mathrm{Ag}-\mathrm{Ca}-\mathrm{Ge}$ system, $\mathrm{kJ} \mathrm{mol}^{-1}$

\begin{tabular}{|c|c|}
\hline$x_{\mathrm{Ag}} / x_{\mathrm{Ge}}$ & \multicolumn{1}{c|}{ Polynomial } \\
\hline $0.30 / 0.70$ & $\begin{array}{l}\Delta H=\left(1-x_{\mathrm{Ca}}\right)\left(2.3-116.9 x_{\mathrm{Ca}}-131.0 x_{\mathrm{Ca}}^{2}+\right. \\
\left.+312.7 x_{\mathrm{Ca}}^{3}\right)\end{array}$ \\
\hline$x_{\mathrm{Ag}} / x_{\mathrm{Ca}}$ & Polynomial \\
\hline $0.25 / 0.75$ & $\Delta H=\left(1-x_{\mathrm{Ge}}\right)\left(-14.2-166.1 x_{\mathrm{Ge}}-59.4 x_{\mathrm{Ge}}^{2}\right)$ \\
\hline $0.50 / 0.50$ & $\begin{array}{l}\Delta H=\left(1-x_{\mathrm{Ge}}\right)\left(-22.9-89.9 x_{\mathrm{Ge}}-98.0 x_{\mathrm{Ge}}^{2}+\right. \\
\left.+226.8 x_{\mathrm{Ge}}^{3}\right)\end{array}$ \\
\hline $0.80 / 0.20$ & $\Delta H=\left(1-x_{\mathrm{Ge}}\right)\left(-16.2-16.8 x_{\mathrm{Ge}}+27.9 x_{\mathrm{Ge}}^{2}\right)$ \\
\hline$x_{\mathrm{Ca}} / x_{\mathrm{Ge}}$ & Polynomial \\
\hline $0.30 / 0.70$ & $\Delta H=\left(1-x_{\mathrm{Ag}}\right)\left(-37.7-8.2 x_{\mathrm{Ag}}+26.5 x_{\mathrm{Ag}}^{2}\right)$ \\
\hline $0.80 / 0.20$ & $\Delta H=\left(1-x_{\mathrm{Ag}}\right)\left(-39.9-39.5 x_{\mathrm{Ag}}+12.8 x_{\mathrm{Ag}}^{2}\right)$ \\
\hline
\end{tabular}

Since the experiments for all investigated cross-sections were carried out up to the limiting molar fraction of the third component, approximately equal to 0.3 , to obtain the integral enthalpies of mixing and corresponding projections of the isolines for the entire concentration range of the Gibbs-Duhem triangle, we performed a model calculation of the $\Delta H$ values for $\mathrm{Ag}-\mathrm{Ca}-\mathrm{Ge}$ melts according to the regular solution model using the Redlich-KisterMuggianu formalism. The complete set of the Redlich-Kister parameters for the constituent binary systems from equation (7) is given in Table 3. The power polynomials from equations (1), (2), and (3) were used as the initial data for the binaries. 
Table 3. Parameters of binary and ternary interaction for the integral enthalpy of mixing $\Delta H$ of liquid alloys of constituent binary $\mathrm{Ca}(\mathrm{Ge})-\mathrm{Ag}, \mathrm{Ge}-\mathrm{Ca}$ and ternary $\mathrm{Ag}-$ $\mathrm{Ca}-\mathrm{Ge}$ systems at $1300-1550 \mathrm{~K}, \mathrm{~kJ} \mathrm{~mol}^{-1}$

\begin{tabular}{|c|c|}
\hline System & Parameter of interaction \\
\hline \multirow[t]{6}{*}{$\mathrm{Ca}-\mathrm{Ag}$} & ${ }^{0} L_{\mathrm{Ca}-\mathrm{Ag}}=-92.0$ \\
\hline & ${ }^{1} L_{\mathrm{Ca}-\mathrm{Ag}}=34.3$ \\
\hline & ${ }^{2} L_{\mathrm{Ca}-\mathrm{Ag}}=12.6$ \\
\hline & ${ }^{3} L_{\mathrm{Ca}-\mathrm{Ag}}=-35.7$ \\
\hline & ${ }^{4} L_{\mathrm{Ca}-\mathrm{Ag}}=3.6$ \\
\hline & ${ }^{5} L_{\mathrm{Ca}-\mathrm{Ag}}=14.1$ \\
\hline \multirow[t]{8}{*}{$\mathrm{Ge}-\mathrm{Ag}$} & ${ }^{0} L_{\mathrm{Ge}-\mathrm{Ag}}=6.91$ \\
\hline & ${ }^{1} L_{\mathrm{Ge}-\mathrm{Ag}}=13.81$ \\
\hline & ${ }^{2} L_{\mathrm{Ge}-\mathrm{Ag}}=0.83$ \\
\hline & ${ }^{3} L_{\mathrm{Ge}-\mathrm{Ag}}=-21.1$ \\
\hline & ${ }^{4} L_{\mathrm{Ge}-\mathrm{Ag}}=-33.8$ \\
\hline & ${ }^{5} L_{\mathrm{Ge}-\mathrm{Ag}}=67.7$ \\
\hline & ${ }^{6} L_{\mathrm{Ge}-\mathrm{Ag}}=27.9$ \\
\hline & ${ }^{7} L_{\mathrm{Ge}-\mathrm{Ag}}=-46.0$ \\
\hline \multirow[t]{6}{*}{$\mathrm{Ge}-\mathrm{Ca}$} & ${ }^{0} L_{\mathrm{Ge}-\mathrm{Ca}}=-223.1$ \\
\hline & ${ }^{1} L_{\mathrm{Ge}-\mathrm{Ca}}=109.9$ \\
\hline & ${ }^{2} L_{\mathrm{Ge}-\mathrm{Ca}}=41.4$ \\
\hline & ${ }^{3} L_{\mathrm{Ge}-\mathrm{Ca}}=-121.4$ \\
\hline & ${ }^{4} L_{\mathrm{Ge}-\mathrm{Ca}}=12.9$ \\
\hline & ${ }^{5} L_{\mathrm{Ge}-\mathrm{Ca}}=42.6$ \\
\hline \multirow[t]{3}{*}{$\mathrm{Ag}-\mathrm{Ca}-\mathrm{Ge}$} & ${ }^{0} L_{\mathrm{Ag}-\mathrm{Ca}-\mathrm{Ge}}=-219.0$ \\
\hline & ${ }^{1} L_{\mathrm{Ag}-\mathrm{Ca}-\mathrm{Ge}}=268.8$ \\
\hline & ${ }^{2} L_{\mathrm{Ag}-\mathrm{Ca}-\mathrm{Ge}}=-26.7$ \\
\hline
\end{tabular}

It should be noted that the constituent binaries of the ternary $\mathrm{Ag}-\mathrm{Ca}-\mathrm{Ge}$ system have different character of the component interaction - from small values changing their sign from positive to negative in the $\mathrm{Ge}-\mathrm{Ag}$ system to strongly exothermic in the $\mathrm{Ge}-\mathrm{Ca}$ one (Figure 4). The deviations of the experimental $\Delta H$ values from those calculated by the regular solution model also vary greatly. Thus, for two crosssections $\left(\mathrm{Ag}_{0.3} \mathrm{Ge}_{0.7} \mathrm{Ca}\right.$ and $\left.\mathrm{Ag}_{0.8} \mathrm{Ca}_{0.2} \mathrm{Ge}\right)$, more exothermic values of the calculated enthalpies of mixing were obtained than the experimental ones. For the other four investigated crosssections, the calculated $\Delta H$ values are less exothermic than the experimentally measured. Evidently, this system can be described adequately using a specific "ternary contribution" term to the integral enthalpy of formation of liquid alloys (the last term in Eq. (7)). The ternary parameters obtained by the least-squares processing of the difference between experimental enthalpies of mixing and those calculated by the Redlich-Kister-Muggianu formalism are shown in Table 3.

The integral enthalpies of mixing, calculated using the specific ternary interaction term are in good agreement with the experimental results within the experimental errors for all studied cross-sections, apart from $\mathrm{Ag}_{0.3} \mathrm{Ge}_{0.7} \mathrm{Ca}$. Thus, we can assume that eq. (7), obtained by the Redlich-Kister-Muggianu model, taking into account the parameters of the ternary interaction, is correct for calculating the enthalpies of mixing of liquid $\mathrm{Ag}-\mathrm{Ca}-\mathrm{Ge}$ alloys for the entire concentration triangle. The topology of isoenthalpies calculated using the Redlich-Kister-Muggianu formalism is shown in Figure 4 with a step of $4 \mathrm{~kJ} \cdot \mathrm{mol}^{-1}$; for a comparison, the integral enthalpies of mixing 
determined experimentally in this study are also presented.

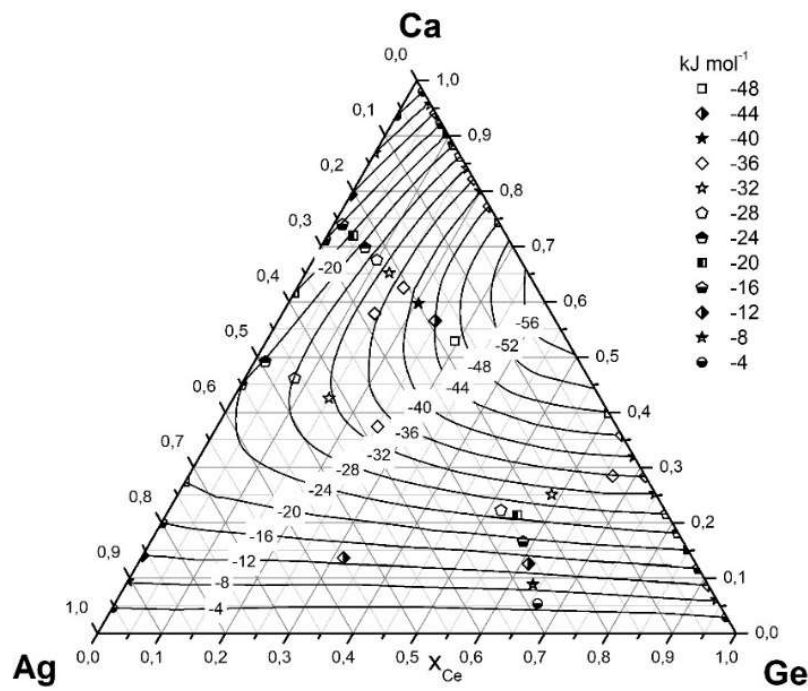

Figure 4. Projections of isolines of the integral enthalpy of mixing of liquid Ag-Ca-Ge ternary alloys at $1300-1550 \mathrm{~K}$ on the concentration triangle, calculated according to the Redlich-Kister-Muggianu formalism with the term of specific ternary interaction (solid lines); the $\Delta H$ values experimentally determined in this work are represented by the corresponding symbols, the step is $4 \mathrm{~kJ} \mathrm{~mol}^{-1}$

Among the three constituent binary systems, the highest exothermic enthalpies of mixing are observed for the liquid $\mathrm{Ca}-\mathrm{Ge}$ alloys. The obtained data on the enthalpies of mixing of ternary melts (Figure 4) allow one to conclude that in the region of compositions close to this binary, the contribution of the interaction between $\mathrm{Ca}$ and $\mathrm{Ge}$ atoms prevails. The maximum interaction is observed at compositions close to congruently melting compounds $\mathrm{Ca}_{2} \mathrm{Ge}$ and $\mathrm{CaGe}$ on the phase diagram of the $\mathrm{Ca}-\mathrm{Ge}$ system (Figure 2, [5]). With increasing in the silver content in the alloy, a gradual decrease in the absolute value of the exothermic enthalpy of mixing towards the $\mathrm{Ag}$ angle of the concentration triangle is observed. This fact can be attributed to a decrease in the fraction of $\mathrm{Ge}$ atoms located in the first coordination sphere of the large $\mathrm{Ca}$ atom due to the replacement of $\mathrm{Ge}$ by $\mathrm{Ag}$ atoms. The interaction of the $\mathrm{Ag}$ with $\mathrm{Ca}$ is much weaker. This fact can be illustrated by the values of the limiting partial enthalpies of mixing of Ge and Ag with $\mathrm{Ca}\left(\Delta H_{\mathrm{Ge}}^{\infty}=-200 \mathrm{~kJ} \cdot \mathrm{mol}^{-1}, \Delta H_{\mathrm{Ag}}^{\infty}=-\right.$ $63 \mathrm{~kJ} \cdot \mathrm{mol}^{-1}$, according to [6] and [4], respectively). Such a decrease in the interaction indicates a much lower ability of silver atoms to accept s-electrons of an active electropositive metal $(\mathrm{Ca})$ compared to germanium atoms in the corresponding binary alloys. This fact can be explained mainly by two factors. First, the difference between the electronegativities of $\mathrm{Ge}$ and $\mathrm{Ca}$ atoms $(\Delta \chi=0.98$, according to AllredRochow [21] is significantly higher than for $\mathrm{Ag}$ and $\mathrm{Ca}(\Delta \chi=0.38)$. Second, the acceptor capacity of the half-filled 4sp-band of germanium in the alloy is higher (it can accept 4 el/atom) than for Ag, which has filled 4d-band and half-filled 5s-band (it can accept 1 el/atom).

With an increase of calcium concentration in the binary $\mathrm{Ca}-\mathrm{Ge}$ alloy, the $4 \mathrm{sp}$ band of germanium is filled with calcium electrons; however, apparently, in this case, the difference in the Fermi energies $\left(\Delta E_{\mathrm{F}}\right)$ of the germanium alloy and metallic calcium remains marked. It is made possible owing to the high initial value of this quantity for pure components 
$\left(\Delta E_{\mathrm{F} \mathrm{Ge}-\mathrm{Ca}}=2 \mathrm{eV},[22]\right)$ and is also due to the relatively high density of the unfilled states in the sp-band of the germanium alloy.

As concerns the Ag-Ca alloys, the initial Fermi energy difference is somewhat lower $\left(\Delta E_{\mathrm{F} \mathrm{Ag}-\mathrm{Ca}}=1.8 \mathrm{eV}\right.$, [22]). Apparently, the density of unoccupied states in the s-band of the $\mathrm{Ag}-\mathrm{Ca}$ alloy is also lower. This results in lower exothermic enthalpies of mixing for these binary alloys.

The smallest exothermic enthalpies of mixing for the ternary alloys are observed when the composition of the ternary alloy approaches the constituent Ag-Ge system. This system is characterized by the least thermal effects of alloy formation. It is due to a relatively strong interatomic interaction in the pure components and minor differences in their electronegativities. Consequently there is no noticeable energy profit when a liquid mixture forms. At concentrations close to the Ag-Ge system, one cannot expect any noticeable concentration of strong germanium-calcium and silver-calcium associates due to the low content of Ca. Thus, a marked decrease in $\mathrm{Ca}$ content in the $\mathrm{Ag}-\mathrm{Ca}-\mathrm{Ge}$ ternary melts leads to the weakening of shortrange order related to the $\mathrm{Ca}-\mathrm{Ge}$ and $\mathrm{Ag}-\mathrm{Ca}$ associates formation. Consequently, the component interaction in the ternary melts decreases.

Finally, the energetics of liquid alloy formation of the $\mathrm{Ag}-\mathrm{Ca}-\mathrm{Ge}$ ternary system is mainly determined by the strong interaction of unlike components in the binary $\mathrm{Ca}-\mathrm{Ge}$ system. The component interaction in the Ag-Ca system is not so strong and less affects it.

\section{Conclusions}

The partial and integral enthalpies of mixing of liquid alloys of the $\mathrm{Ag}-\mathrm{Ca}-\mathrm{Ge}$ ternary system have been determined for the first time via high-temperature calorimetry in the temperature range $1300-1550 \mathrm{~K}$. The surface of the enthalpies of mixing has been calculated according to the regular solution model using the Redlich-Kister-Muggianu method, taking into account the specific ternary interaction term for the entire concentration triangle. A comparison of the calculated and experimentally determined thermochemical properties of liquid alloys of the $\mathrm{Ag}-\mathrm{Ca}-\mathrm{Ge}$ ternary system has been carried out. The obtained values of the enthalpies of mixing were compared with the component interaction in the constituent binary systems. It was found that the enthalpies of mixing are significant exothermic values with a minimum of about -56 $\mathrm{kJ} \mathrm{mol}^{-1}$ in the concentration region close to the $\mathrm{Ca}_{0.6} \mathrm{Ge}_{0.4}$ composition. The exothermic effects of mixing decrease in absolute value towards the Ag angle of the concentration triangle. The enthalpy of alloy formation in the $\mathrm{Ag}-\mathrm{Ca}-\mathrm{Ge}$ ternary system is mainly determined by the strong interaction of unlike components in the $\mathrm{Ca}-\mathrm{Ge}$ liquid binary system. At the same time, the component interaction in the $\mathrm{Ag}-\mathrm{Ca}$ liquid system less affects it. 


\section{References}

[1] Wang J, Chartrand P, Jung In-Ho. Thermodynamic description of the $\mathrm{Ag}-(\mathrm{Ca}, \mathrm{Li}, \mathrm{Zn})$ and $\mathrm{Ca}-(\mathrm{In}$, Li) binary systems. CALPHAD. 2015; 50: 68-81.

[2] Depbski A, Debski R, Gaşior W, Góral A. Formation enthalpy of intermetallic phases from $\mathrm{Ag}-\mathrm{Ca}$ system. Experiment vs. modeling. J. Alloys Compd. 2014; 610: 701-705.

[3] Huang GX, Liu LB, Jia BR, Zhang LG, Jin ZP. Thermodynamic modeling of the $\mathrm{Ca}-\mathrm{Ag}$ binary system $\mathrm{J}$. Alloys Compd. 2008; 460 (1-2): 375-378.

[4] Ivanov MI, Berezutski VV, Usenko NI. Mixing enthalpies in $\mathrm{Ag}-\mathrm{Ca}, \mathrm{Ag}-\mathrm{Eu}$ and $\mathrm{Ag}-\mathrm{Yb}$ liquid alloys. Int. J. Mat. Res. 2009; 100(7): 1001-1004.

[5] Palenzona A, Manfrinetti P, Fornasini ML. The phase diagram of the $\mathrm{Ca}-\mathrm{Ge}$ system. J. Alloys Compd. 2002; 345: 144-147.

[6] Shevchenko MO, Ivanov MI, Berezutski VV, Sudavtsova VS. Thermodynamic Properties of Alloys in the Binary Ca-Ge System. J. Phase Equilib. Diff. 2015; 36: 554-572.

[7] Mejbar J. These de Doctorat. l'Universite de Nancy I. 1993.

[8] Delsante S, Borzonea G, Novakovic R. Experimental thermodynamics, surface and transport properties of liquid Ag-Ge alloys. Thermochim. Acta. 2019; 682: 178432.

[9] Rajkumar VB, Chen S-W. Phase equilibria and thermodynamic descriptions of $\mathrm{Ag}-\mathrm{Ge}$ and $\mathrm{Ag}-\mathrm{Ge}-\mathrm{Ni}$ systems. J. Electron. Mater. 2018; 47(7): 3666-3677.

[10] Massalski TB, Okamoto H, Subramanian PR, Kacprzak L (Eds.) Binary Alloy Phase Diagrams. 2nd Edition., ASM International, Materials Park, Ohio, 1990; 1-2: 39-42.

[11] Bellissent-Funel M-C, Desré PJ, Bellissent R, Tourand G. Structure of liquid eutectic Ag-Ge by neutron diffraction. J. Phys. F: Metal. Phys. 1977; 7(12): 2485-2494.

[12] Kazimirov VP, Roik OS, Perevertailo VM, Loginova OB, Lisovenko SA. The nature of the ordering of atoms in a melt and the surface properties of simple eutectic systems. J. Superhard Mater. 2008; 30(4): 241-254.

[13] Eremenko VN, Lukashenko GM, Pritula VL. Thermodynamic properties of liquid solutions in the argentumgermanium system. Izv. Akad. Nauk SSSR Neorg. Mater. 1967; 3(9): 1584-1590 (in Russian).

[14] Batalin GI, Beloborodova EA, Stukalo VA. Thermodynamic properties of germanium and argentum molten alloys. Zh. Fiz. Khim. 1971; 45(10): 2697 (in Russian).
[15] Hultgren R, Desai PD, Hawkins DT, Gleiser M, Kelly KK. Selected Values of Thermodynamics Properties of Binary Alloys. ASM International, Metals Park, OH. 1973: $57-$ 61 .

[16] Usenko NI, Ivanov MI, Petiuh VM, Witusiewicz VT. Thermochemistry of binary liquid alloys of copper with barium and lanthanide metals (europium, dysprosium and ytterbium). J. Alloys Compd. 1993; 190(2): 149-155.

[17] Usenko N, Kotova N, Ivanov M, Berezutski V. Mixing enthalpies in binary $\mathrm{Ce}-\mathrm{Sb}$ and ternary $\mathrm{Ce}-\mathrm{Co}-\mathrm{Sb}$ liquid alloys. Int. J. Mat. Res. 2013; 104(1): 46-50.

[18] Dinsdale AT. SGTE data for pure elements. CALPHAD. 1991; 15(4): 317-425.

[19] Darken LS. Application of the Gibbs-Duhem Equation to Ternary and Multicomponent Systems. J. Am. Chem. Soc. 1950; 72(7): 2909-2914.

[20] Hillert M. Empirical methods of predicting and representing thermodynamic properties of ternary solution phases. CALPHAD. 1980; 4: 1-12.

[21]https://www.webelements.com/periodicity/eneg_a llred_rochow/

[22] De Boer FR, Boom R, Mattens WCM, Miedema AR, Niessen AK. Cohesion in Metals. North-Holland, Amsterdam; 1988, 758. 